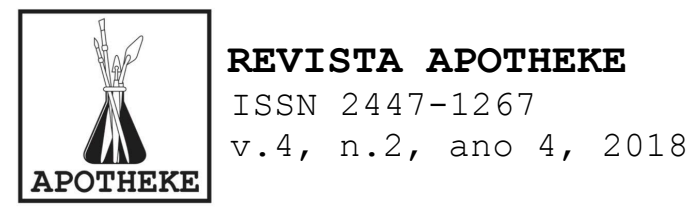

\title{
Exercícios para uma poética da solidariedade
}

\author{
Alice Fátima Martins (UFG, CNPq)
}

\section{RESUMO}

Neste texto, é feita uma crítica ao binômio arte e não-arte, tomando como base a noção de arte de matriz europeia, expandida pelos processos de colonização, a partir da era moderna. Como desdobramento da discussão proposta, busca-se esboçar alguns parâmetros para uma poética da solidariedade, fundada na natureza das relações de vínculo entre as pessoas no exercício da sensibilidade, nos processos de criação e compartilhamento. PALAVRAS-CHAVE: arte; não-arte; experiências compartilhadas; poética da solidariedade.

\section{ABSTRACT}

Based on the notion about art shaped on European thought, this paper develops a critical approach to the binomial art/non-art. This notion has been expanded during the colonization processes, in the Modern period. So, the purpose of this reflection is to outline some parameters for a poetic of solidarity, based on the nature of the relationship between people in the exercise of creating processes and sharing.

KEYWORDS: art; non-art; sharing experience; poetics of solidarity.

\section{Daquilo que é chamado de arte...}

Em torno à arte, foi tecida uma aura de fios invisíveis que mantém uma espécie de imantação para o campo, mesmo em tempos quando prevalece a reprodutibilidade técnica das imagens, nos aparatos tecnológicos. A arte tem poder transformador, é o que se diz. Também se argumenta ser possível, por meio dela, ampliar horizontes, transgredir normas, questionar as estruturas hegemônicas vigentes. Reivindica-se, para a arte, exercícios de liberdade (o que quer que isso signifique...). É recorrente a afirmação de que a arte não se sujeita a definições. Indefinível, imponderável, inquestionavelmente necessária, indispensável: são atribuições nem sempre coerentes entre si, mas facilmente reconhecíveis quanto a temática se volta ao trabalho artístico, mesmo em tempos marcados pelos prefixos pós e hiper: pós-modernos, pósestruturalistas, pós-históricos, hipervisuais, hiperconectados, etc.

Mas do que se está tratando, ao referir-se à arte? 


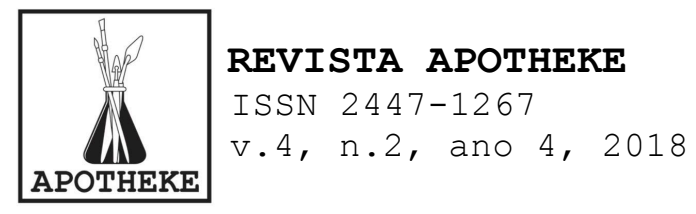

É preciso notar que a noção de arte com a qual se opera de modo hegemônico nos circuitos de formação acadêmica, e no próprio sistema da arte, surgiu na Europa renascentista, e funda-se em bases teóricas da filosofia, da ética e da estética forjadas pelo pensamento grego, do qual essa matriz é herdeira direta. A expansão dessa noção (e de outras tantas...) deu-se durante a modernidade, tendo sido possível graças à expansão geográfica e econômica, nos processos de colonização protagonizados pelos países europeus nas grandes navegações iniciadas à época.

Em outras palavras, essa concepção da arte implica num tipo de atividade da cultura, no âmbito da construção de sentidos, forjado a partir de um contexto social e histórico específico. Portanto, não é atemporal, tampouco universal. Se, de um lado, a noção de arte, ou de obra de arte, não é universal, de outro lado, as plurais comunidades humanas têm desenvolvido diferentes práticas sociais que articulam construção de sentidos, encantamentos, sensibilidade, experiência estética, sem, contudo, nominá-las como arte, ou submetê-las ao protocolo ocidental de matriz europeia daquilo que seja considerado arte.

Para Colombres (2005, p. 271),

\begin{abstract}
la gran ventaja que da a Occidente disponer de una vasta teoría estética, que data ya de casi 25 siglos, unida al poder económico y político que detentan los llamados "países centrales", hizo posible que esta concepción invadiera numerosos contextos culturales donde tal fenómeno no existía, o se daba con características muy disímiles. ${ }^{1}$
\end{abstract}

Assim, se os países com vocação imperial, esses chamados "países centrais", não economizaram esforços em seus

\footnotetext{
1 A grande vantagem que dá ao Ocidente dispor de uma vasta teoria estética, que data de quase 25 séculos, unida ao poder econômico e político de que são portadores os chamados "países centrais", fez possível que esta concepção invadisse numerosos contextos culturais onde tal fenômeno não existia, ou se dava com características muito distintas. (tradução livre).
} 
empreendimentos com vistas à dominação do "outro", a noção dominante de arte prestou-se, também, a tal projeto. Ou seja, esta concepção de arte, ao lado da religião e do poder econômico, cumpriu papel central nos processos de colonização, cuja viabilização dá-se em vários níveis, desde o geográfico, humano, passando pelo econômico, ocupando o simbólico e o imaginário.

Qual a conformação dessa noção de arte à qual este texto faz referência? Já foi dito que o conceito de arte com que se opera atualmente não data de muito tempo, tendo sido forjado na modernidade. Do mesmo modo, o termo artesão, ou a noção de artesanato (que estabelece relações de antagonismo com a arte) é recente, e decorre exatamente da separação entre as artes superiores, as belas artes, de um lado, e as artes menores, mecânicas, de outro. No contexto europeu, até o século XV, artista e artífice tinham sentidos muito próximos, e a noção de arte aparecia como um saber fazer, um conjunto específico de habilidades. Os mestres de ofícios, nas corporações, desenvolviam suas atividades de modo rigoroso, orientadas por segredos de seu saber fazer.

Quando, sob a pressão das mudanças que decorreram da circulação dos objetos para consumo, bem como da ascensão de interesses por parte das elites em relação aos artefatos que lhes atribuíssem distinção, as atividades das corporações entraram em declínio, com a consequente desvalorização da figura do mestre de ofício. Em lugar do artífice, emergiu a figura do artista dotado de múltiplas habilidades, portador de mistérios advindos de algum manancial próprio, de uma certa genialidade inexplicável e irreprodutível, único, um dom, e cuja arte poderia estar disponível para atender (sempre a bom preço) às vicissitudes dos desejos dos poderosos no tocante às suas representações e imaginários.

Neste ponto, acentuou-se a separação entre artistas e artesãos, já deflagrada pelas dinâmicas do mercado e dos 


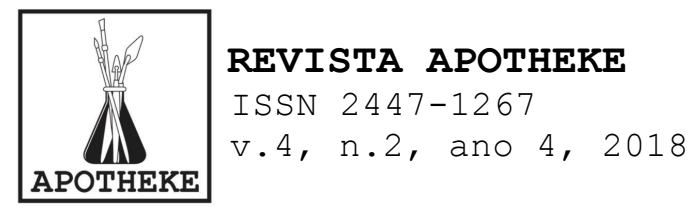

interesses de diferentes clientelas: as classes mais poderosas, em busca de marcas de distinção produzidas por artistas, de um lado, e as necessidades de infraestrutura atendidas pelos artesãos, de outro.

Foi entre os séculos XV e XVII que surgiram as Academias. Inicialmente constituídas por ciclos esporádicos de encontros abertos ao público, por parte de mestres, com programações não estáveis, ofereceram espaços para que os artistas-artesãos pudessem ampliar sua visão para além dos muros de seu ambiente de trabalho, confrontando-os com outros valores e orientações metodológicas (RUGIU, 1998). Esses espaços foram sistematizados gradativamente, organizando uma pedagogia formal que veio substituir o "aprender fazendo" das Corporações. Ali se configurou a figura do artista que reconhecia mais afinidades com um poeta do que um trabalhador braçal.

Nesse processo, às práticas artesanais, que não desapareceram, mas sofreram profundas transformações com a Revolução Industrial, foram atribuídas qualidades tais como obsolescência, resistência ao progresso, tradição, repetição, realização mecânica sem base conceitual. Em contraposição ao artesanato, a arte compareceu com seu tratado no qual reivindicava, para si, a instauração do novo, o rompimento com qualquer compromisso com o passado, a singularidade, a inovação, o ato criador prenhe de desinteresse pelas questões utilitárias.

Durante um Festival de Arte na Cidade de Goiás, realizamos uma instalação numa das praças. Ela fazia parte de um projeto de arte inspirado nas ideias da estética relacional (BORRIAUD, 2011), denominado Nós \& Nós (MARTINS \& ROCHA, 2013). Foi montado um dispositivo com muitos materiais têxteis, e algumas estruturas básicas de onde se podiam partir quaisquer modos de tessitura, amarrações, e outras invenções. Esse material foi disponibilizado às pessoas, passantes, 


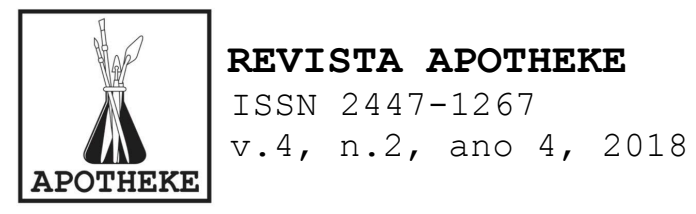

estudantes, para interagirem da forma como quisessem. As crianças, sobretudo, brincavam entre os fios, fazendo grandes algazarras e emaranhados enormes. Nas cercanias, alguns moradores que teciam tapetes e outras artesanias ficavam observando o movimento. Alguns chegaram a perguntar "que serventia" tinha aquilo que nós estávamos fazendo. Chamavam a atenção para o fato de que aquele material era bom para fazer uns tapetes. Participaram do processo lúdico ali proposto, mas não partilharam totalmente da ideia, pois a todo tempo o seu ofício os convocava a pensar nos objetos utilitários que poderiam produzir com aquele material em risco de se estragar, de se extraviar, ali na praça. Ao final do festival, se apropriaram da estrutura e dos fios, que desapareceram rapidamente do local da instalação. Àquele emaranhado, foram dadas outras funções, regidas por outras mãos.

\section{Das coisas que são não-arte...}

Tapetes feitos a mão não são arte. nem madeira entalhada para ornar portas, portões, janelas, batentes, e quantos outros itens usados quotidianamente. Nem redes macias para se repousar. Tampouco panelas de barro são arte. ou vestidos bordados, ou chapéus de couro, traçados, rebordados. Integram - território das coisas utilitárias, mesmo quando sua realização manual implique em segredos desse fazer, ou rituais acessíveis tão somente a iniciados. Cartograficamente, essas práticas culturais são cuidadosamente colocadas no grande círculo das coisas que são não-arte.

Para Colombres (2005), o problema da arte é justamente tudo quanto se coloca fora da arte. Ora, é de se notar que o conceito europeu de arte foi introduzido nas Américas no século XVIII, e em África, nas primeiras décadas do século XX. Nesses contextos, acumulam-se as práticas e os trabalhos considerados não-arte, ou enquadrados como artesanato, por não coincidirem, em seus projetos, com a noção de arte portada 


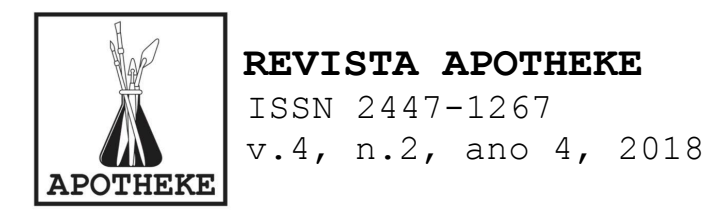

pelos colonizadores. Mas a noção de artesanato tampouco corresponde às categorias próprias das culturas desenvolvidas nesses territórios desde antanho, sendo impingida a elas desde uma referência que lhes é totalmente estranha, qual seja o medievo europeu. O autor argumenta, ainda, que a importância de tais práticas está não só em manifestarem aspectos mais específicos das matrizes simbólicas de seus próprios contextos, mas principalmente porque constituem um campo de resistência à colonização visual, e o melhor ponto de partida para se pensar o universal. Não cabe, aqui, também, a noção de um universal dominante, singular, monolítico, mas se trata de uma perspectiva múltipla, pautada pela diversidade, pela diferença, pela complexidade. Em horizontes desenhados pela alteridade e pela solidariedade.

\section{De insurgências dentro do mundo da arte}

Considerando ainda o campo da arte em suas especificidades, não se pode deixar de considerar que está marcado, periodicamente, por rebeliões e reivindicações autorreferidas como contranormativas, que deflagraram mudanças conceituais e nos referenciais estéticos predominantes a cada ciclo, ou nos vetores que disputaram relevância entre si. No início do século XX, por exemplo, às portas da Primeira Guerra Mundial, pintores, poetas, pacifistas, músicos de várias nacionalidades europeias se reuniam no Cabaret Voltaire, em Zurique, o solo neutro da Suíça, para se manifestar contra toda sorte de autoridades e instituições estabelecidas. A arte incluía-se nesse rol, considerada por esse grupo como pequenoburguesa e decadente. A expressão Dadá, uma espécie de balbuciar infantil, de quem ainda não sabe falar, pretendia reduzir a cacos, no âmbito da arte, tudo quanto fosse considerado válido até então. Não mais se utilizaria tinta a óleo para pintar, nem se observariam as regras da norma culta para produzir textos na literatura. Uma espécie de antiarte 


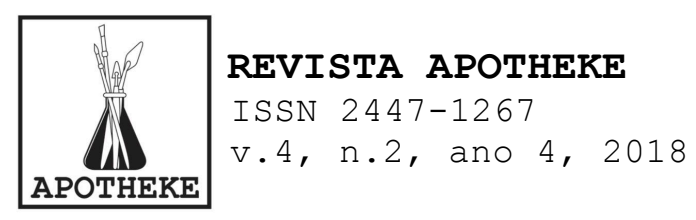

(conceito bem distinto da não-arte), questionando os cânones artísticos diante da destruição da guerra, e do domínio da lógica do mercado sobre a cultura.

Contudo, a rebeldia instaurava-se sem escapar ao próprio território de instalação da arte. Por isso mesmo, a antiarte viria a ser capitalizada pelo mercado, que não se demorou em declará-la arte, portanto devidamente legitimada pelo sistema da arte. Assim, o Dadá foi incorporado aos museus e seus espaços expositivos, preservados por seus estatutos e conjuntos normativos. Paradoxalmente, sujeitou-se a eles.

Em 2016, uma série de programações foi realizada em vários países, em celebração aos 100 anos do manifesto Dadá. No final de setembro daquele ano, a cidade de Goiânia foi alçada à condição de capital brasileira do Dadá. Denominado DadáSpring, evocou uma espécie de "Primavera Dadá", como um levante, uma força que se mobiliza para questionar o establishment. Muitas ações foram articuladas às atividades universitárias, outras em espaços públicos. A maior parte ocorreu na casa onde se reúnem os artistas do Grupo Empreza ${ }^{2}$ desde o início dos anos 2000, e se desenvolvem atividades artísticas as mais variadas. Selando a semana de intensas manifestações, oficinas, instalações e intervenções, instalouse, à porta da casa-sede das atividades, a placa oficial do Cabaret Voltaire, uma réplica da existente no Cabaret Voltaire de Zurique.

Contudo, as ações deflagradas não tiveram repercussão fora dos circuitos formados por artistas, intelectuais, produtores culturais, estudantes universitários que atuam nos campos das artes. A força questionadora e autocrítica esgota-

2 o Grupo Empreza integra artistas de origens diversas, com formação flutuante, em ação desde o início dos anos 2000. Seus trabalhos, refjeridos como do campo da performance, também podem ser pensados como ações artísticas que articulam o corpo em crise, política e crítica institucional. Mais informações podem ser acessadas em <https://www.grupoempreza.com/>. 


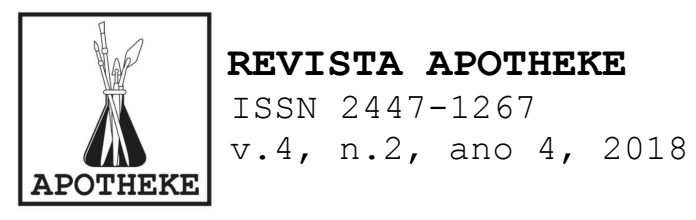

se nos domínios intramuros do próprio sistema das artes. Mas é possível considerar outra possibilidade: a força questionadora e autocrítica cumpre papel central nos processos de renovação do território artístico, ainda sem extrapolar os protocolos e os territórios demarcados por esse sistema.

O mesmo pode ser observado em quantas outras manifestações contemporâneas da arte, assim como em projetos que pretendam realçar mudanças na natureza das relações entre - trabalho artístico e o público. Nesses termos, propostas que jogam com referenciais da estética relacional (BOURRIAUD, 2011) consideram que a experiência sensível não se localiza num objeto artístico dado, ou presença do público ante um trabalho previamente realizado, mas está na relação entre as pessoas com os espaços propostos. O artista assume, então, o papel de propositor, de deflagrador de processos aos quais o público é convidado a tomar parte ativa, como protagonista. O trabalho artístico assim pensado está aberto às relações possíveis e ao inesperado, incorpora novas marcas, podendo se reestruturar a partir de interferências mais radicais (MARTINS \& ROCHA, 2013).

No entanto, aqui também se cumpre um redimensionamento formal da arte, de transformações na natureza das relações entre objeto e trabalho artístico, artista e público, sem, contudo, escapar aos fundamentos do sistema no qual essas relações se dão. Tendo isso em vista, é inevitável a pergunta: como seria possível pensar a experiência sensível insurgente aos protocolos do sistema da arte? A quem interessaria um tal exercício?

\section{Sobre a natureza das relações entre as pessoas, e das pessoas com o meio em que vivem}

A experiência sensível, o potencial criador, o interesse por aquilo que afeta os sentidos não se restringe ao campo da arte definido a partir da matriz europeia, disseminada pelos colonizadores, conforme enfatiza Colombres (2005). Tal 


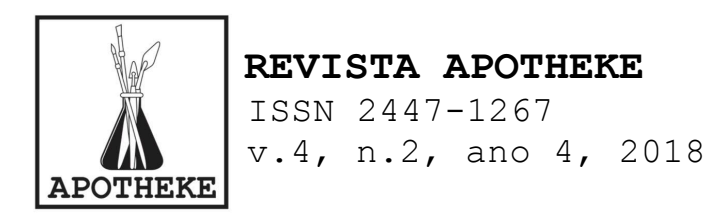

constatação não pode ser considerada novidade, tampouco inaugural. Mesmo assim, a possibilidade de tecer algumas considerações a respeito, bem como rememorar projetos e experiências nessa direção, mostra-se necessária para possibilidades tanto para repensar o próprio contexto da arte, no cenário contemporâneo, quanto apontar para possibilidades que equacionem, com base em outros parâmetros, práticas de produção simbólica, expressiva, sensível.

Embora não nomeasse nesses termos suas linhas de ação, desde o final dos anos 1960, no Planalto Central do Brasil, a artista de múltiplas facetas e educadora Laís Fontoura Aderne Faria Neves, mais conhecida como Laís Aderne desenvolveu um trabalho inspirador nessa direção. Amparada nas ideias de Paulo Freire, ela deflagrou, a partir da cidadela olhos D’Água, vários projetos e processos envolvendo questões relativas aos saberes locais, à cultura, às relações interpessoais, à economia solidária, ao meio ambiente. A possibilidade do exercício envolvendo as dimensões sensíveis da vida não se dissociava das demais dimensões, e por isso ganhava sentidos mais fecundos e duradouros.

Dentre as iniciativas que deixaram sua marca, está a Feira do Troca, realizada regularmente desde o início dos anos 1970, e assegurada até estas cercanias dos anos 2020, mesmo tendo transcorrido mais de uma década da morte de sua mentora, em 2007. A Feira, com duas edições anuais, conta com a participação de toda a comunidade local, e recebe visitantes de várias cidades vizinhas. A base inicial de sua organização estava na possibilidade de trocas de serviços, objetos e outros bens produzidos pela comunidade, marcados pelos traços culturais. Na Feira, bens utilitários entrelaçam-se aos simbólicos e à beleza, de modo indiferenciado, sem que as categorias arte e não-arte cumpram qualquer papel nos modos de organização. Privilegiam-se, ali, as redes de pertencimento, o fortalecimento dos vínculos comunitários, bem como o 


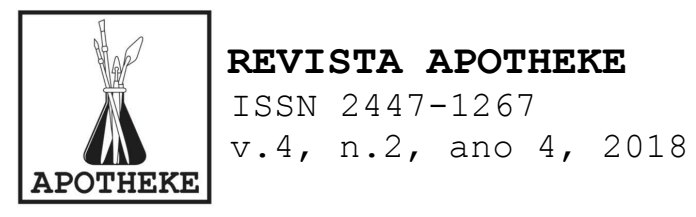

acolhimento, pelo coletivo, das manifestações particulares, de caráter mais individual.

Ressalte-se que a formação original de Laís Aderne está nas artes plásticas, tendo estudado na Escola de Belas Artes de Belo Horizonte e posteriormente na Escola Nacional de Belas Artes, no Rio de Janeiro, onde foi orientada por Osvaldo Goeldi, no início da década de 1960. Também trabalhou na Escolinha de Arte do Brasil, onde ministrou cursos de gravura, pintura e desenho para adolescentes e adultos. Por isso, os projetos desenvolvidos por ela não perderam de vista a defesa da inclusão, nos projetos educativos, das questões relativas à arte. Numa perspectiva que redimensionava a natureza dessa inclusão, ela convocava os educadores, no tocante ao ensino de artes, a uma ação mais anarquista do que acadêmica, em favor da multiplicidade de manifestações da cultura brasileira, da diversidade de manifestações, e da necessidade de uma educação fundada nas referências culturais das comunidades das quais as instituições escolares fazem parte.

As teias dessas ações estendiam-se entre as escolas e os demais espaços da comunidade. "Ela fazia o trabalho dela confiando nas pessoas, então, como ela confiava na gente, a gente confiava nela também", relata Dona Nega das Bonecas, no vídeo realizado por zé Nobre sobre a Feira do Troca (RELICÁRIO, 2018). Os princípios da reciprocidade e da solidariedade, que se podem observar nessa fala, transpiravam, por exemplo, nos encontros entre mulheres que fiavam e teciam, entre cantorias, conversas, biscoitos e chás. Dali, desdobravam-se projetos, providências, aprendizagens. Em espaços e práticas como aquelas, fortaleciam-se os vínculos comunitários.

Naquelas ações, experiência poética, cultura, meio ambiente e comunidade mostravam-se indissociáveis. O mesmo pode ser observado em outro projeto, desenvolvido a partir de contexto diverso do de Laís Aderne. Intitulado Bordando por la 


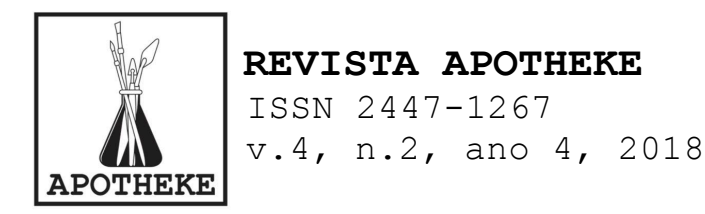

Paz y la Memoria, foi deflagrado na Cidade do México, a partir de 2011, ganhando desdobramentos em cidades de outros países, tanto latino-americanos quanto além mar. Naquele ano, um grupo de artistas, pesquisadores e ativistas começaram a reunir-se, semanalmente, num espaço público para bordar a mão pequenos panos brancos, registrando os nomes de mortos e desaparecidos pela guerra do narcotráfico. Convocando a comunidade para essa jornada artística, o grupo desafiava a indiferença das autoridades em relação à questão. Ao analisar tal ação, Rico (2018) ressalta o fato de uma tal ação ocorrer numa realidade social marcada pela violência e pela pauperização crescente da população, em meio à exortação das pessoas à produtividade, subtraindo disponibilidades para a defesa dos interesses comunitários. Diante desse quadro, a autora pergunta pelo sentido de reunir grupos de modo provisório para narrar, com linha e agulha, o assassinato de pessoas muitas vezes desconhecidas. Indaga, também, pela natureza das relações que podem ter se estabelecido entre as pessoas participantes, durante esse tempo dedicado ao registro dos homicídios.

Rico (2018) argumenta que ações dessa natureza, com base em experiências concretas, aparecem como alternativas que se contrapõem aos modos de acumulação capitalista, funcionando como um espelho invertido ao que tem sido negado por essa lógica dominante: a solidariedade, a reciprocidade, a mútua dependência entre os seres humanos vivendo com comunidade. Assim, sem descartar a possibilidade de que os voluntários participantes das jornadas, nas atividades de bordado compartilhadas, tenham construído espaços de encontro, estabelecendo vínculos de confraternização, o bordado a várias mãos operou com formas de pertencimento e solidariedade. Destaca-se o sentido do coletivo articulando as experiências individuais, bem como a relevância do sentido colaborativo, em rede. Do mesmo modo, coloca-se o desafio das noções de autoria 


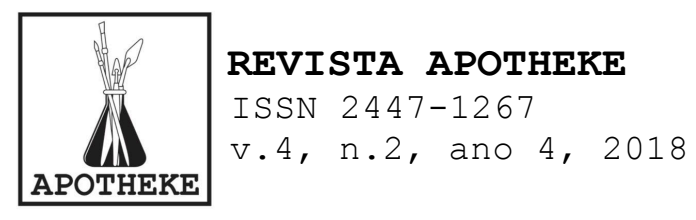

e propriedade, na medida em que os guardanapos bordados são de todos e de ninguém, ao mesmo tempo.

Avançando sobre a noção de rede e compartilhamento, o projeto ganhou diversas páginas em plataformas digitais de relacionamentos sociais, nas quais são compartilhadas produções, experiências e convocações para os desdobramentos dos encontros em múltiplos contextos. No Brasil, por exemplo, mulheres das etnias Guarani e Kaiowa, em 2015, bordaram os nomes de pessoas de suas relações mortas nos conflitos pelas questões territoriais. O registro desse trabalho está compartilhado na rede mundial de computadores.

\section{Primeiros rascunhos de um (des) caminho...}

Os trabalhos desenvolvidos por Laís Aderne, no Planalto Central do Brasil, e pelo grupo mexicano, multiplicado em grupos pelo continente afora, atravessando mares, reportam um tipo de projeto no qual, independentemente do trabalho executado, ou dos resultados obtidos, a ênfase recai nos encontros entre as pessoas, no compartilhamento de experiências, no fortalecimento dos vínculos.

Não se trata de se reivindicar maior valor aos processos deflagrados do que aos seus resultados, os produtos finais. De fato, há um deslocamento, nesses dois casos reportados: a natureza das relações entre as pessoas é que estão em vista, o compartilhamento de seus projetos. Tal compartilhamento é mediado por atividades que dão conta da produção simbólica, seja na forma de narrativas, de artefatos, de ações objetivas. Num certo sentido, a ética vai ao encontro da experiência poética, desdobrando-se, ambas, sobre a própria vida, como meios de produção de sentidos para as comunidades. A própria noção de comunidade também se mostra afeita a abordagens diversas: podem ser comunidades voláteis em torno aos projetos em curso, ou comunidades mais estáveis que compartilham uma relação tempo/espacial de modo mais complexo. Podem, ainda, 


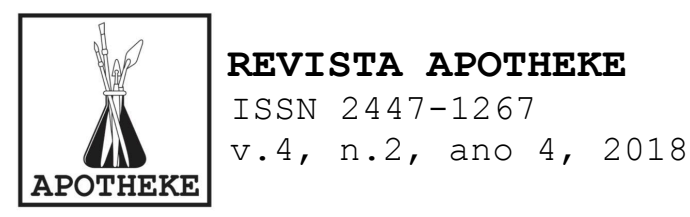

ser comunidades institucionalizadas, tais como as escolares, ou de asilos, hospitais, etc.

Laís Aderne articulava questões relativas à cultura, práticas comunitárias, fazeres poéticos, ao meio ambiente e à sustentabilidade. Nasceram daí alguns projetos de ecomuseus. Os guardanapos bordados com os nomes de pessoas mortas ou desaparecidas estão marcados, de fato, por afetos compartilhados, num movimento que se estende entre gentes que, mesmo sem se conhecerem, comungam de sentimentos e desejos próximos.

Projetos, trabalhos desenvolvidos com essa natureza não têm lugar no sistema da arte. Do mesmo modo, as vestes da arte não lhe caem de modo confortável. Habitam, tais práticas, territórios que atravessam os protocolos da noção de arte de matriz europeia, estendendo-se em direção a comunidades outras, e a experiências sensíveis orientadas por outros vetores. Nesses, os princípios da solidariedade, da reciprocidade, da partilha antecipam-se aos que fazeres, orientando suas dinâmicas. E dão o tom dos laços que se estabelecem a partir desses que fazeres.

É nesses termos que se rascunham possibilidades de uma poética da solidariedade, como utopia compartilhada, como sentido de humanidade redimensionado pela poesia. Como resistência aos processos de colonização sem subalternidade. Seus descaminhos podem até transitar os territórios das coisas consideradas arte, mas não se ocupam demasiado delas. Sua ênfase recai, sobretudo, no grande círculo das coisas insignificantes consideradas não-arte, a partir das quais é possível tecer e recriar sentidos outros, estabelecer e restabelecer vínculos, nutrir afetos.

\section{Referências}

BORRIAUD, Nicolas. Estética relacional. São Paulo: Martins Fontes, 2011. 


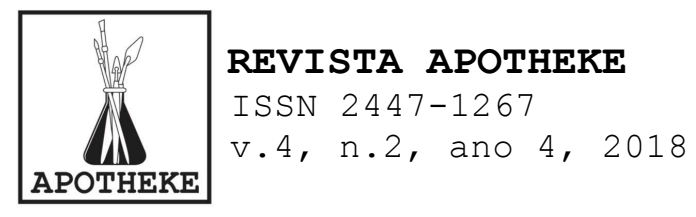

COLOMBRES, Adolfo. Teoría transcultural del arte: hacia um pensamiento visual independiente. Buenos Aires: Del Sol, 2005.

MARTINS, Alice Fátima; ROCHA; Cleomar. Arte relacional em uma poética colaborativa: NÓS \& NÓS. In MEDEIROS, Afonso; HAMOY, Idanise, (Orgs.) Anais do $22^{\circ}$ Encontro Nacional de Pesquisadores em Artes Plásticas: Ecossistemas Estéticos. Belém: ANPAP; PPGARTES/ICA/UFPA, 2013.

RELICÁRIO Olhos d'Água. Vídeo. Direção e produção: Zé Nobre. Duração: $18 \mathrm{~min}$. Disponível em

<https://www.youtube.com/watch?v=e6kjPxZ450o>, Acesso em 13 jun. 2018 .

RICO, Katia Olalde. Cartografias críticas. Volumen I. Los Angeles: California State University, 2018.

RUGIU, Antonio Santoni. Nostalgia do mestre artesão. Campinas: Autores Associados. 1998. 